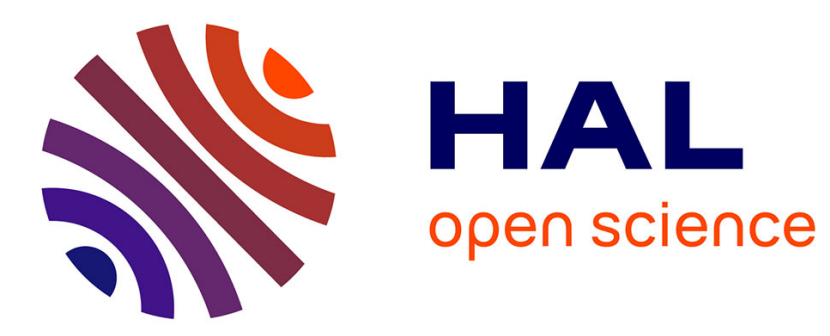

\title{
Tuning the thermal stability of copper(II) hexacyanoferrate(II)
}

\author{
Micheal P Moloney, Nicolas Massoni, Agnès Grandjean
}

\section{To cite this version:}

Micheal P Moloney, Nicolas Massoni, Agnès Grandjean. Tuning the thermal stability of copper(II) hexacyanoferrate(II). Journal of Thermal Analysis and Calorimetry, 2020, 145 (5), https://doi.org/10.1007/s10973-020-09823-4. 10.1007/s10973-020-09823-4 . cea-03561207

\section{HAL Id: cea-03561207 https://hal-cea.archives-ouvertes.fr/cea-03561207}

Submitted on 8 Feb 2022

HAL is a multi-disciplinary open access archive for the deposit and dissemination of scientific research documents, whether they are published or not. The documents may come from teaching and research institutions in France or abroad, or from public or private research centers.
L'archive ouverte pluridisciplinaire $\mathbf{H A L}$, est destinée au dépôt et à la diffusion de documents scientifiques de niveau recherche, publiés ou non, émanant des établissements d'enseignement et de recherche français ou étrangers, des laboratoires publics ou privés.

\section{(1) (1) $\$$}

Distributed under a Creative Commons Attribution - NonCommercial - NoDerivatives $\mid 4.0$ 


\title{
Tuning the thermal stability of Copper (II) Hexacyanoferrate(II) nanoparticles
}

\author{
Mícheál P Moloney, ${ }^{\mp ¥}$ Nicolas Massoni, ${ }^{\mp}$ Agnès Grandjean ${ }^{¥}$
}

\begin{abstract}
${ }^{\mp}$ CEA, DEN, Univ. Montpellier, DE2D, SEAD, Laboratory of Supercritical and Decontamination Processes, , F30207 Bagnols-sur-Cèze, France

¥ CEA, DEN, Univ. Montpellier, DE2D, SEVT, Research Laboratory for the development of conditioning matrices, F-30207 Bagnols-sur-Cèze, France
\end{abstract}

\begin{abstract}
It is well known that the physical properties of nanoparticles can be tuned by controlling synthetic factors such as $\mathrm{pH}$, temperature, reactant ratio or type of stabiliser used. In this work the reactant ratio is varied to produce batches of Copper (II) Hexacyanoferrate (II) (Cu-HCF) with different cyano decomposition temperatures. This is accomplished by controlling the number of $\mathrm{Fe}(\mathrm{CN})_{6}{ }^{4-}$ site vacancies throughout the structure. By reducing the number of vacancies, and consequently the need for water to complete the structure, the thermal decomposition temperature of $\mathrm{Cu}-\mathrm{HCF}$ can be increased. In addition to this we also note that the guest ion similarly contributes to the decomposition temperature. By exchanging $\mathrm{K}^{+}$with $\mathrm{Cs}^{+}$an increased resistance to thermal decomposition is realised. As the incorporation of $\mathrm{Cs}^{+}$ ions into the structure does not alter the number of $\mathrm{Fe}(\mathrm{CN})_{6}{ }^{4-}$ site vacancies this enhancement is attributed to a change in the geometry of the copper co-ordination sphere.
\end{abstract}

\section{Introduction}

Hexacyanoferrates (HCFs) of various transition metals have once again begun to attract attention as sorbents in the selective extraction of $\mathrm{Cs}^{+}$ions. ${ }^{1,2,3,4,5,6,7,8,9,10}$ This is due to their high sorption capacity for caesium over a wide $\mathrm{pH}$ range, in high salinity, and their high stability. ${ }^{11,12,13,14,15}$ In case of K-Hexacyanoferrates of transition metals, and especially $\mathrm{Cu}$ $\mathrm{HCF}$, the $\mathrm{Cs}^{+}$sorption mechanism occurs via an ionic exchange between $\mathrm{K}^{+}$from the solid structure and $\mathrm{Cs}^{+}$from the solution. ${ }^{16}$ Although polynuclear supramolecular complexes these materials can also be classified as nanoparticles, (Figure 1). ${ }^{17,18}$ It is well recorded in the 
literature that in the nanodomain, materials begin to exhibit unique properties, due in some cases to their size and in others to their high surface area to mass ratio. ${ }^{19,20}$ Understanding and controlling these properties is vital to engineering nanomaterials with the desired properties. Particle properties can be tuned by controlling experimental factors such as the $\mathrm{pH}$, temperature, type of stabiliser used, or even reactant ratio during synthesis. ${ }^{21,22,23}$ For example by varying the metal to non-metal ratio in luminescent quantum dots it is possible to tune both their size and quantum yield. ${ }^{24}$ In this work we propose to use one of the aforementioned techniques (reactant ratio) to determine if it is possible to tune the physical properties (thermal resistance) of $\mathrm{Cu}-\mathrm{HCF}$. It is well known that it is possible to produce $\mathrm{Cu}-\mathrm{HCF}$ with varied $\mathrm{Cu}, \mathrm{Fe}, \mathrm{H}_{2} \mathrm{O}$ and $\mathrm{K}$ content. ${ }^{7}$ Here, we report that by controlling the $\mathrm{Cu}: \mathrm{Fe}$ ratio we tune the amount of structural water present in each batch, this in turn affects the thermal stability of the cyano ligands. Finally by exchanging the guest ion, $\mathrm{K}^{+}$for $\mathrm{Cs}^{+}$, it was possible to further increase the thermal stability of the cyano ligand. This was attributed to the decreased interaction of the $\mathrm{Cs}^{+}$guest ions with the structural water.

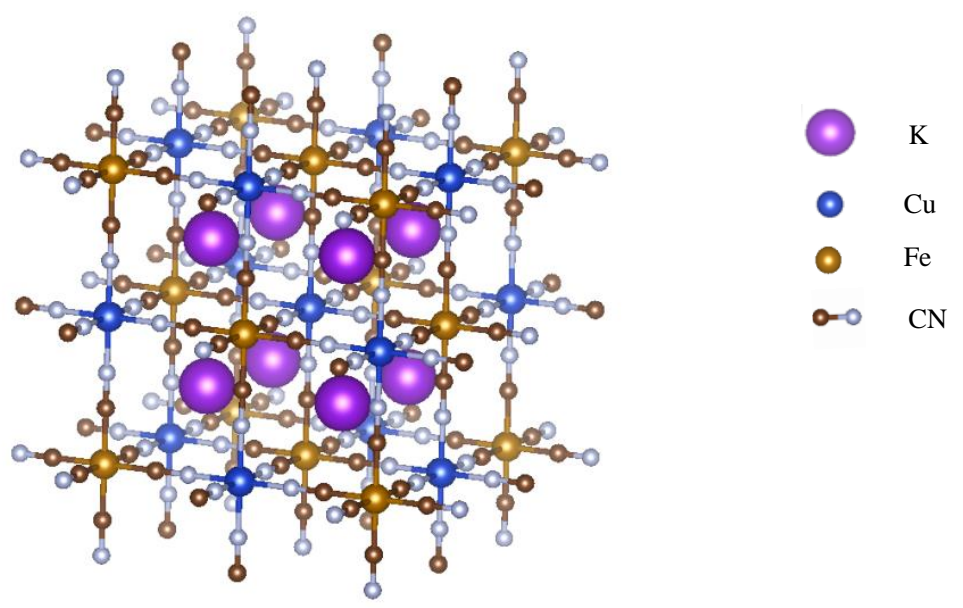

Figure 1: Schematic representation of the structure of $\mathrm{K}_{2} \mathrm{CuFe}(\mathrm{CN})_{6}$ in which none of the $\mathrm{Fe}$ sites are vacant.

In this work, five separate batches of $\mathrm{Cu}-\mathrm{HCF}$ (II) were prepared by a simple co-precipitation reaction that gives nanoparticles as previously reported. ${ }^{9}$ Each batch contained a different ratio of $\mathrm{Cu}^{2+}$ to $\mathrm{Fe}(\mathrm{CN})_{6}^{4-}$ ions at moment of contact (i.e. before co-precipitation). Batch 1 was prepared using an initial $0.5: 1$ ratio of $\mathrm{Cu}^{2+}$ to $\mathrm{Fe}(\mathrm{CN})_{6}{ }^{4-}$, this was increased to $1: 1,1.5: 1,2: 1$ and 2.5:1 for batches 2, 3, 4 and 5 respectively. Elemental analysis (EA) and TGA of the final products confirmed different $\mathrm{Cu}$ to $\mathrm{Fe}$ ratios as well as $\mathrm{K}$ and water content, (Table 1). Interestingly, it was also found that despite 5 different initial reactant ratios being used only three distinct particle stoichiometries were created. This suggests that there are preferred 
stoichiometries. FT-IR and XRD demonstrated that as we move across the 3 stoichiometries the material is consistently copper (II) hexacyanoferrate (II) with no changes in the oxidation state being observed. However, these techniques were used in conjunction with each other to highlight the (re)arranging of the $\mathrm{Fe}(\mathrm{CN})_{6}{ }^{4-}$ vacancies as well as changes in the local $\mathrm{Cu}$ chemical environments as the copper ratio was increased. Finally, TGA and FT-IR were used to show an increase in the thermal stability of the $\mathrm{CN}$ ligand as the copper to iron ratio approached 1:1. We believe that this is due to a dependence on the quantity of structural water within the material. That is, as the number of Fe vacancies (and therefore number of moles of structural water) are decreased, the higher the thermal stability of the material will be. Finally, the replacement of $\mathrm{K}^{+}$with $\mathrm{Cs}^{+}$as the guest ion caused a further increase in the thermal stability of the material. While $\mathrm{Cs}^{+}$sorption does not affect the amount of structural water it does cause a change in the copper co-ordination sphere as noted by FT-IR. It is assumed that the $\mathrm{Cs}^{+}$(as with $\mathrm{K}^{+}$) guest ions interact with the structural water partially sharing it with the copper. ${ }^{25}$ By replacing $\mathrm{K}^{+}$with an ion which does not interact as strongly with water this allows for a strengthening/shortening of the $\mathrm{Cu}-\mathrm{OH}_{2}$ bond. ${ }^{26,27}$

\section{Experimental}

$\mathrm{K}_{4}\left[\mathrm{Fe}(\mathrm{CN})_{6}\right] .3 \mathrm{H}_{2} \mathrm{O}, \mathrm{CsNO}_{3}$ and $\mathrm{Cu}\left(\mathrm{NO}_{3}\right)_{2} .3 \mathrm{H}_{2} \mathrm{O}$ were purchased from Sigma-Aldrich. Millipore water was used in the synthesis of the Copper (II) Hexacyanoferrate (II) particles.

Copper (II) Hexacyanoferrate (II), here on referred to as $\mathrm{Cu}-\mathrm{HCF}$ (II), was prepared by the direct addition of a volume (V1) of an aqueous (Millipore) $1.5 \times 10^{-1} \mathrm{M} \mathrm{Cu}\left(\mathrm{NO}_{3}\right)_{2} .3 \mathrm{H}_{2} \mathrm{O}$ solution to a fixed volume (V2) of a $1 \times 10^{-1} \mathrm{M}$ aqueous solution of $\mathrm{K}_{4}\left[\mathrm{Fe}(\mathrm{CN})_{6}\right] .3 \mathrm{H}_{2} \mathrm{O}(\mathrm{K}-$ $\mathrm{HCF}$ ). The $\mathrm{Cu}$ :Fe ratio was controlled by modifying the ratio V1 to V2. Five batches in total were produced with an initial $\mathrm{Cu}$ to Fe ratio of i). 0.5:1, ii). 1:1, iii). 1.5:1, iv). 2:1 and v). 2.5:1. Upon addition of the blue coloured copper solution to the light yellow K-HCF solution a dark burgundy coloured precipitate was immediately formed. The contents of the reaction vessel were then allowed to mix for an hour by rotary mixing. The resulting solid was then collected by centrifugation and washed several times with Millipore water. As the washing steps accumulate, batches 1 and 2 become more and more stable in water and therefore acetone (50\% v/v) was needed as a non-solvent to help crash out the particles. This is assumed to be because of the majority presence of $\mathrm{Fe}(\mathrm{CN})_{6}$ groups on their surfaces. ${ }^{28}$ Once the washing steps are complete (4 washes) the $\mathrm{Cu}-\mathrm{HCF}$ was dried under rotary evaporation at $60{ }^{\circ} \mathrm{C}$. The resulting 
dark solid was then examined using Elemental Analysis (EA), DLS, FT-IR, TGA, and XRD. As it is possible to monitor the concentration of $\mathrm{K} 4 \mathrm{Fe}(\mathrm{CN})_{6}$ and $\mathrm{Cu}\left(\mathrm{NO}_{3}\right)_{2}$ in solution via UVVis active the supernatant of each batch was examined by UV-Vis after the particles were removed.

Chemical compositions were measured by inductively coupled mass spectrometry for $\mathrm{Cu}, \mathrm{Fe}$, $\mathrm{K}$, (and Cs for exchanged sample) after particles were dissolved via microwave radiation in $\mathrm{HNO}_{3}$. Water content was determined using TGA. It has been shown that TGA results for HCF's can vary with heat rate, mass of sample, or even the type of crucible used. ${ }^{29}$ Therefore, when examining the samples in this work all three aforementioned factors were kept constant. TGA experiments were taken between $30-300^{\circ} \mathrm{C}$ in air at a heating rate of $30{ }^{\circ} \mathrm{C} / \mathrm{min}$, using a Mettler Toledo TGA/DSC 1 star $^{\mathrm{e}}$ system. Sample mass was kept constant at $20 \mathrm{mg}$. Crucibles did not have lids placed on them.

The crystalline structure was identified using powder XRD which were performed using a Panalytical X'Pert MPD Pro spectrometer in a Bragg-Brentano geometry. A copper tube $(\lambda=1,5406 \AA)$ with a nickel filter was used with an X'Célérator detector. Typical measurement was completed in $5 \mathrm{~h}$ between 10 and $90^{\circ} 2 \theta$. The X-Ray refinements were profile matching done with the Fullprof freeware included in the Toolbar Fullprof Suite V. July-2017.

Chemical structure was studied using FT-IR. The measurements were carried out using a Nicolet iS50.

Zetapotential and size measurements were carried out in water using a Malvern Nano ZS.

Thermal behaviour was also followed using FT-IR. Each batch was taken and placed in an oven where it was heated in air to the desired temperature and allowed to stand at this temperature for 4 hours before being cooled and examined by FT-IR.

K/Cs exchanges were conducted using a high concentration Cs solution $(700 \mathrm{mg} / \mathrm{L} \mathrm{Cs}$; source $\mathrm{CsNO}_{3}$ ). Each experiment consisted of contacting $100 \mathrm{mg}$ of dried samples with $100 \mathrm{~mL}$ of the above mentioned solution. Langmuir Isotherms (SI) confirmed this concentration was sufficient for each batch to reach its respective Cs capacity. 


\section{Results and discussion}

\section{Chemical Composition}

Elemental analysis (EA) and TGA were used to determine if changing the ratio of $\mathrm{Cu}\left(\mathrm{NO}_{3}\right)_{2}$ to $\mathrm{K}_{4} \mathrm{Fe}(\mathrm{CN})_{6}$ would alter the actual particle stoichiometry, including guest ion and water content. These techniques were vital as they allowed for the ascertainment of the exact degree of vacancies, and consequently the $\mathrm{H}_{2} \mathrm{O}$ and $\mathrm{K}$ content within the particles. The results of these analyses are displayed in table 1. [ Oxidation numbers for each compound reported on table 1 do not amount to zero. However, this $2-4 \%$ discrepancy falls well within the elemental analysis $10 \%$ margin of error.] The most striking result is the enforcement of what appears to be three distinct population types throughout the series.

$\underline{\text { Batches } 1 \text { and } 2}$ produce almost identical results with $1.27 \pm 0.01 \mathrm{Cu}$ for every Fe. Both of these results show a considerably higher $\mathrm{Cu}$ to $\mathrm{Fe}$ ratio than the initial reactant ratio. This ratio seems to be desired as $\mathrm{UV}-\mathrm{Vis}$ of the supernatants confirmed that $\mathrm{K}_{4} \mathrm{Fe}(\mathrm{CN})_{6}$ was still available to both batches.

$\underline{\text { Batch } 3}$ is composed of $\mathrm{Cu}-\mathrm{HCF}$ particles with a final ratio of $1.66 \mathrm{Cu}$ to every $1 \mathrm{Fe}$. [Considering there is a $10 \%$ error in the EA analysis this final stoichiometry is very close to that of the reactant ratio of 1.5:1.] UV-Vis shows no $\mathrm{Fe}(\mathrm{CN})_{6}$ or $\mathrm{Cu}\left(\mathrm{NO}_{3}\right)_{2}$ present in the supernatant.

Batches 4 and 5 both show 1.9 Cu's for every Fe. This is in good agreement for batch 4's reactant ratio of 2:1 but not batch 5's, this indicates that we have reached $\max \mathrm{Cu}^{2+}$ to $\mathrm{Fe}(\mathrm{CN})_{6}{ }^{4}$.

Table 1: ICP-MS: moles of $\mathrm{Cu}, \mathrm{K}$ and $\mathrm{Fe}$ in all 5 batches, water content was calculated from TGA results. Data has been normalised with respect to $\mathrm{Fe}$. Note: * $\left(\mathrm{Cu}\right.$ to $\mathrm{Fe}$ reactant ratio), ${ }^{\S}(\mathrm{Cu}$ to $\mathrm{Fe}$ ratio in final product).

$\begin{array}{cccccc}\text { Batches } & \mathbf{C u}: \mathrm{Fe}^{*} & \mathbf{C u} \S & \mathbf{F e} & \mathbf{K} \S & \text { Formula } \\ 1 & 0.5: 1 & 1.26 & 1 & 1.69 & \mathrm{~K}_{1.69} \mathrm{Cu}_{1.26} \mathrm{Fe}(\mathrm{CN})_{6.1 .3 \mathrm{H}_{2} \mathrm{O}} \\ 2 & 1: 1 & 1.28 & 1 & 1.60 & \mathrm{~K}_{1.6} \mathrm{Cu}_{1.28} \mathrm{Fe}(\mathrm{CN})_{6} \cdot 1.3 \mathrm{H}_{2} \mathrm{O} \\ 3 & 1.5: 1 & 1.66 & 1 & 0.82 & \mathrm{~K}_{0.82} \mathrm{Cu}_{1.66} \mathrm{Fe}(\mathrm{CN})_{6.3 .7 \mathrm{H}_{2} \mathrm{O}} \\ 4 & 2: 1 & 1.90 & 1 & 0.34 & \mathrm{~K}_{0.34} \mathrm{Cu}_{1.9} \mathrm{Fe}(\mathrm{CN})_{6.5 .4 \mathrm{H}_{2} \mathrm{O}} \\ 5 & 2.5: 1 & 1.90 & 1 & 0.33 & \mathrm{~K}_{0.33} \mathrm{Cu}_{1.9} \mathrm{Fe}(\mathrm{CN})_{6} .5 .4 \mathrm{H}_{2} \mathrm{O}\end{array}$


The aforementioned preparations were repeated multiple times to confirm the results. The fact that no batch resulted in a $1: 1$ ratio of $\mathrm{Cu}$ to $\mathrm{Fe}(\mathrm{CN})_{6}$ indicates that the presence of a certain number of $\mathrm{Fe}(\mathrm{CN})_{6}$ vacancies seems to be energetically desirable. These results suggest a minimum (1.3:1) and maximum $(1.9: 1) \mathrm{Cu}^{2+}$ to $\mathrm{Fe}(\mathrm{CN})_{6}^{4-}$ range in which stable $\mathrm{Cu}-\mathrm{HCF}$ particles can be produced.

EA also showed that the $\mathrm{K}$ concentration decreased as $\mathrm{Cu}$ increased. This is understandable as the guest $\mathrm{K}^{+}$ions act as charge balancers in this material. As the ratio of the cationic $\mathrm{Cu}^{2+}$ to anionic $\mathrm{Fe}_{(\mathrm{II})}(\mathrm{CN})_{6}{ }^{-4}$ is increased, the need for cationic $\mathrm{K}^{+}$will be reduced. Finally, the water content was calculated using TGA. It showed that as the copper content increased so too did the water content. This is also understandable as water is used to complete coppers coordination sphere when cyano ligands are unavailable. TGA showed the water content to be $5 \%, 15.4 \%$ and $20 \%$ (weight $\%$ ) for batches 2,3 and 4 respectively. Combining this with the previously discussed elemental analysis data it gives the structural formulas $\mathrm{K}_{1.6} \mathrm{Cu}_{1.28} \mathrm{Fe}(\mathrm{CN})_{6} .1 .3 \mathrm{H}_{2} \mathrm{O}$ - (type I) , $\mathrm{K}_{0.82} \mathrm{Cu}_{1.66} \mathrm{Fe}(\mathrm{CN})_{6} .3 .7 \mathrm{H}_{2} \mathrm{O}$ - (type II) and

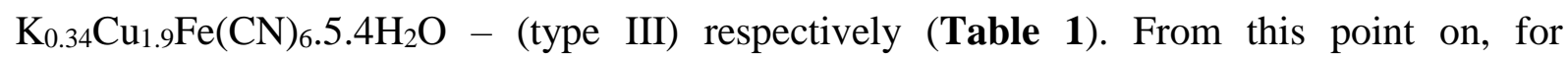
simplicities sake, only batches 2, 3 and 4 will be examined as they represent the three population types.

\section{Structural properties of $\mathrm{Cu}-\mathrm{HCF}$ types}

XRD

XRD of the three types (batches 2, 3 and 4) showed that they all possessed an F-centred cubic unit cell, (Figure 2). ${ }^{30}$ Rietveld refinement showed that the lattice constants were $a=10.0421 \pm$ $0.0175 \AA, a=10.0039 \pm 0.0040 \AA$ and $a=10.0007 \pm 0.0042$ respectively. This decrease in size could be due to the decrease in $\mathrm{K}^{+}$content as seen in the elemental analysis, ${ }^{7}$ or perhaps it might also be a result of the increased copper content enhancing the already strong copper cyano back bonding effect. ${ }^{31,32}$ While the three XRDs scans are quite similar there are slight differences which are clearly visible between each batch. These differences are small, quite broad, additional reflections in batches 3 and 4 at $12.5^{\circ}, 20^{\circ}, 21.5^{\circ}$ and $26.5^{\circ}$ which do not belong to the Bragg reflections of the Fm3m space group. It was found that a Pm3m cubic fit worked better here. As Jiménez-Gallegos et $\mathrm{al}^{33}$ pointed out, when closely examining the structure of cubic hexacyanoferrates their vacancy distribution is normally random and therefore the 
structure can be assigned to a Fm3m structural model. However, as the vacancies begin to become more organised a Pm3m model is a more accurate fit (Figure 2). ${ }^{33}$

It should also be noted that in the case of the Fm3m space group, copper is assigned a single chemical environment of $\mathrm{Cu}(\mathrm{NC})_{4}\left(\mathrm{OH}_{2}\right)_{2}$. Conversely, in the $\mathrm{Pm} 3 \mathrm{~m}$ fit $\mathrm{Cu}$ is assumed to have several environments. (This point will be raised again in the FT-IR section.) Finally, the reflections in batches 3 and 4 are narrower when compared to batch 2; the narrowing of the peaks indicates an increase in sample crystallinity.

Therefore, moving from type I (batch 2) to type III (batch 4), as the $\mathrm{Cu}$ :Fe ratio is increased the Fe vacancy distribution becomes less random and several $\mathrm{Cu}$ environments are created. There is also an increase in the crystallinity.

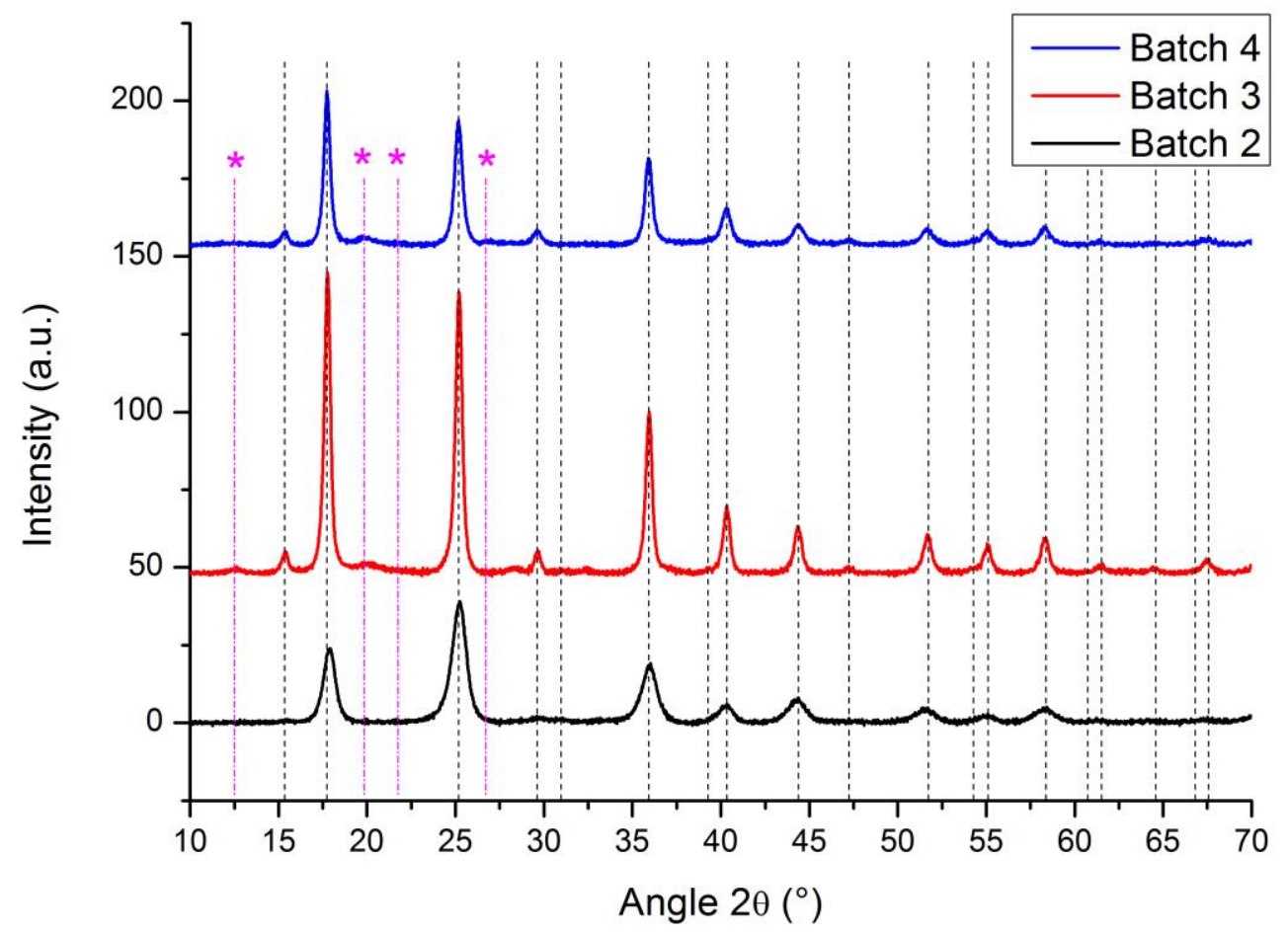

Figure 2: XRD of batches 2 (black), 3 (red) and 4 (green). The black dotted vertical lines are the Bragg reflections for a Fm3m space group. The purple vertical lines indicated with an asterisk are respectively the $1^{\text {st }}, 4^{\text {th }}, 5^{\text {th }}$ and $7^{\text {th }}$ supplementary Bragg reflections from a Pm3m space group (remaining reflections were either superimposed with the Fm3m ones or omitted for clarity) 


\section{FT-IR}

In the FT-IR spectra of transition metal hexacyanoferrates (HCF's) three regions are concentrated on. These are i). the M-L region between $400 \mathrm{~cm}^{-1}-900 \mathrm{~cm}^{-1}$, ii). the $\mathrm{v}(\mathrm{CN})$ region from $1,900 \mathrm{~cm}^{-1}-2,200 \mathrm{~cm}^{-1}$, and finally iii). two separate water regions one between 1,500 $\mathrm{cm}^{-1}-1,700 \mathrm{~cm}^{-1}$ and the second between $3,000 \mathrm{~cm}^{-1}$ to $4,000 \mathrm{~cm}^{-1} \cdot 32,34,35$, The exact position of these peaks, especially the very prominent $\mathrm{v}(\mathrm{CN})$ stretch, is dependent on a). the type of metals present and b). their oxidation state(s). The sensitivity of these peaks to their local environment therefore makes FT-IR an invaluable tool when characterising these compounds. ${ }^{36}$ $v(C N)$ region from $1,900 \mathrm{~cm}-1-2,200 \mathrm{~cm}-1$

Generally speaking, for $\mathrm{Cu}-\mathrm{HCF}$ (II) the $\mathrm{v}(\mathrm{CN})$ stretch can be found at around 2,080 $\mathrm{cm}^{-1}$, with an increase in frequency to $2,180 \mathrm{~cm}^{-1}$ if the $\mathrm{HCF}$ iron is oxidised from $\mathrm{Fe}^{(\mathrm{II})}$ to $\mathrm{Fe}^{(\mathrm{III})} \cdot 31,35 \mathrm{As}$ the $\mathrm{v}(\mathrm{CN})$ of all samples remains around $2,080 \pm 10 \mathrm{~cm}^{-1}$ we can say with a fair amount of certainty that throughout the series of experiments Fe remains in the (II) oxidation state (Figure 3).

The $\mathrm{v}(\mathrm{CN})$ of batch 2 is recorded at $2,070 \mathrm{~cm}^{-1}$. This shifts to $2,090 \mathrm{~cm}^{-1}$ and $2,091 \mathrm{~cm}^{-1}$ for batch 3 and 4 respectively. This increase in energy indicates a strengthening of the cyano bonds. $\mathrm{Cu}^{2+}$ has the ability to fill its $3 \mathrm{~d}$ shell by receiving electrons from the CN's $5 \sigma$ orbital. ${ }^{32}$ These bonds are further strengthened by the cyano's ability to accept electrons from the copper in a back donation via a $\pi$ bond into the cyano's anti-bonding $\pi$-orbital. ${ }^{31}$ By increasing the number of coppers relative to the numbers of cyano ligands we increase the back donated electron density, this in turn strengthens the cyano bond and causes the $\mathrm{v}(\mathrm{CN})$ to increase in frequency.

\section{$M-L$ region between $400 \mathrm{~cm}^{-1}$ to $900 \mathrm{~cm}^{-1}$}

Looking to the M-L region the $\mathrm{v}(\mathrm{Fe}-\mathrm{C})$ stretch, was recorded at $590 \mathrm{~cm}^{-1}, 594 \mathrm{~cm}^{-1}, 593 \mathrm{~cm}^{-1}$ respectively for batch 2, 3 and 4 . This is in good agreement for $\mathrm{Cu}-\mathrm{HCF}$ (II), as its v(Fe-C) is normally seen at around $595 \mathrm{~cm}^{-1}$, (Figure 3 - Inset II). ${ }^{35}$

While this is all noteworthy a more drastic change takes place when looking at the second signal(s) in the M-L region, the $\mathrm{v}(\mathrm{Cu}-\mathrm{N})$. Depending on the copper to iron ratio this peak can appear as either a broad singlet, or well-structured doublet. This splitting of the $\mathrm{v}(\mathrm{Cu}-\mathrm{N})$ peak can be explained by the presence of a Jahn-Teller tetragonal distortion within the $\mathrm{Cu}$ octahedral. ${ }^{37}$ Looking to Figure 3 we would tend to agree with this assignment, especially as the presence of the second peak becomes more and more evident as the copper to iron ratio is increased. This is in good agreement with what was previously seen in the XRD, i.e. the 
creation/enhancement of a second $\mathrm{Cu}$ environment. Starting with Batch 2 the $\mathrm{v}(\mathrm{Cu}-\mathrm{N})$ is seen as a broad peak at $472 \mathrm{~cm}^{-1}$ with a partially hidden shoulder at $488 \mathrm{~cm}^{-1}$ (Figure 3 - Inset II). As the copper ratio is increased the shoulder (now at $494 \mathrm{~cm}^{-1}$ ) becomes more structured and increases in strength. This shows that a). multiple copper environments are present, and b). that they are dependent on the $\mathrm{Fe}: \mathrm{Cu}$ ratio.
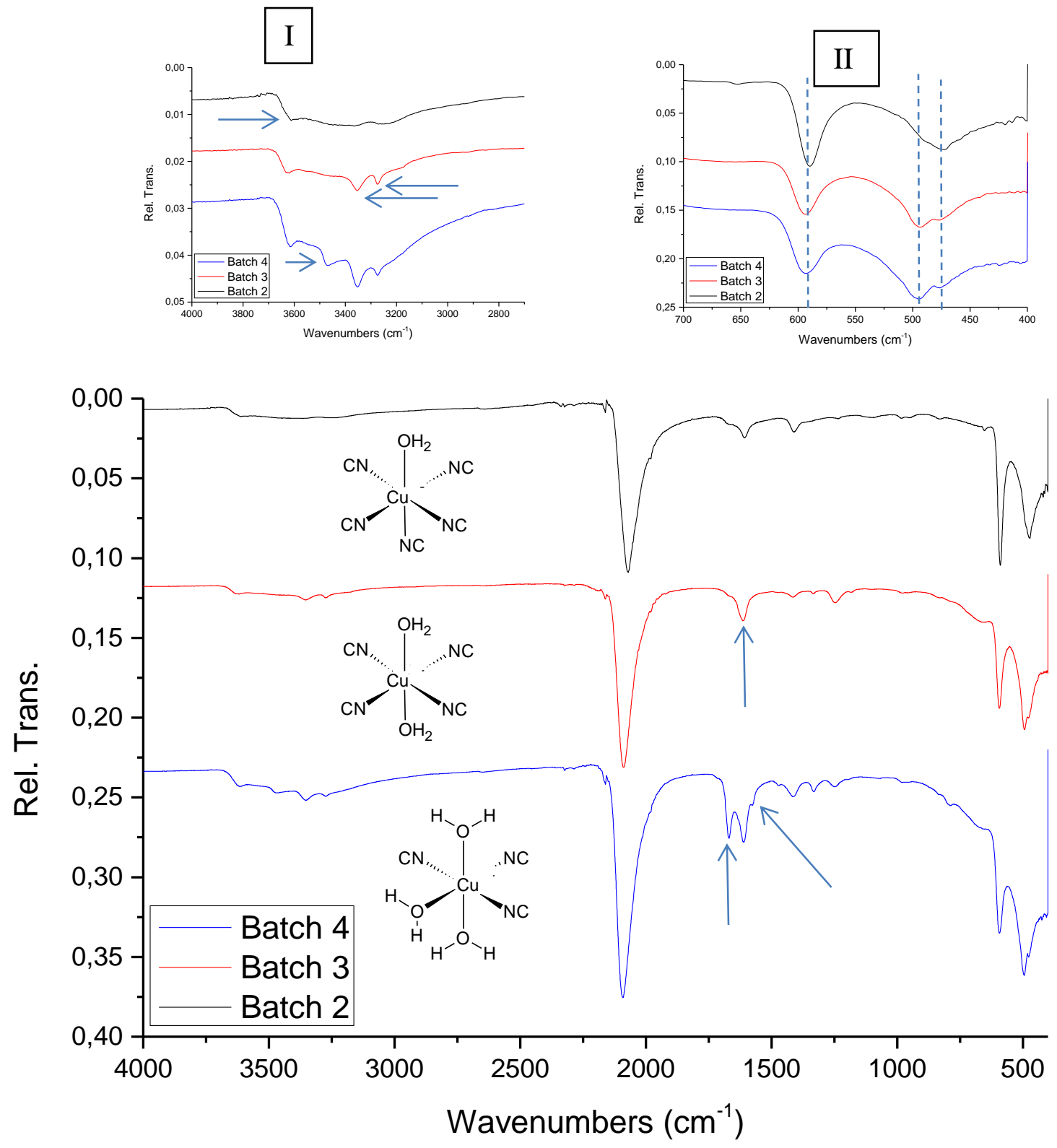

Figure 3: FT-IR of batches 2 (black), 3 (red) and 4 (blue) Cu-HCF. Note the increase in the number of co-ordinated water peaks as the copper to iron ratio is increased. 


\section{Water Signals}

This assessment (multi-copper environment) is supported when looking at the water regions of the spectra. HCF's possess two types of water, structural (co-ordinated water) and zeolithic (non-structural water molecules present in the pores). Structural water is $\mathrm{H}_{2} \mathrm{O}$ which is coordinated to the hetero-metal (in this case copper) centres of the structure. These molecules are needed to complete the crystal unit where one or more of the $\mathrm{Fe}(\mathrm{CN})_{6}{ }^{4-}$ units are missing. It is for this reason that they are referred to as structural water. FT-IR can distinguish between structural and zeolithic water. Coordinated (structural) water can be identified by the presence of well-structured peaks, the $\delta(\mathrm{HOH})$ stretches found between $1600 \mathrm{~cm}^{-1}-1700 \mathrm{~cm}^{-1}$, and the $\mathrm{v}(\mathrm{OH})$ stretches between $3,500 \mathrm{~cm}^{-1}$ to $4,000 \mathrm{~cm}^{-1}$. The second type of water (zeolithic) is not structural and can be considered to be "free", or more likely, loosely bound through hydrogen bonding to any crystalline water present nearby. However, these bonds are relatively weak and therefore this type of water is usually characterised by the presence of a broad hump like structure between $3,000 \mathrm{~cm}^{-1}$ to $3,500 \mathrm{~cm}^{-1}$.

As shown in Figure 3, FT-IR of batch 2 displays a $\delta(\mathrm{HOH})$ peak and shoulder at $1600 \mathrm{~cm}^{-1}$ and $1,660 \mathrm{~cm}^{-1}$ respectively. As the copper ratio is increased the shoulder at $1,660 \mathrm{~cm}^{-1}$ continues to grow and sharpen eventually becoming a peak in batch 4, (Figure 3). Batch 4 also displays a third $\delta(\mathrm{HOH})$ water peak beginning to appear at $1,576 \mathrm{~cm}^{-1}$. the $\mathrm{v}(\mathrm{OH})$ region shows for batch 2 a single relatively well-structured coordinated $\mathrm{v}(\mathrm{OH})$ peak at 3,565 $\mathrm{cm}^{-1}$ with two broad hump-like peaks present nearby at 3,402 $\mathrm{cm}^{-1}$ and 3,240 $\mathrm{cm}^{-1}$, are also seen, (Figure 3 - Inset I). In batch 3 we see that is now consists of three distinct peaks with a forth added in batch 4 . In all cases, the zeolithic humps are still visible, though diminished, (Figure 3 - Inset I). All of this demonstrates not only an increase in the type of co-ordinated water as we increase the $\mathrm{Cu}$ to $\mathrm{Fe}$ ratio but also an increase in the number of co-ordinated water environments.

Inset in Figure 3 show the representations of each batches average $\mathrm{Cu}(\mathrm{NC})_{\mathrm{x}}\left(\mathrm{OH}_{2}\right)_{\mathrm{y}}$ copper coordination sphere to the closet whole number. According to EA copper in batches 2, 3 and 4 will have 4.8, 3.6 and 3.1 cyano ligands respectively. The remaining spots in the octahedron are occupied by water molecules.

\section{DLS}

Zeta potential measurements of batches 2, 3 and 4 showed the surface charge of each batch to be $-45.4 \mathrm{mV},-31.7 \mathrm{mV}$ and $-27.7 \mathrm{mV}$ respectively, (Figure 4). The greater surface negativity 
of batch 2 suggests a surface less dominated by hydrated copper than batches 3 or 4 . This is also reflected in the aggregate sizes, where increased amounts of surface cyano aid in particle dispersion. ${ }^{9}$ The reduction in surface charge as the $\mathrm{Cu}: \mathrm{Fe}$ ratio increased is believed to be due to the greater presence of hydrated $\mathrm{Cu}$ (as opposed to cyano groups) on the particles surfaces as we move from batch 2 to 4 .
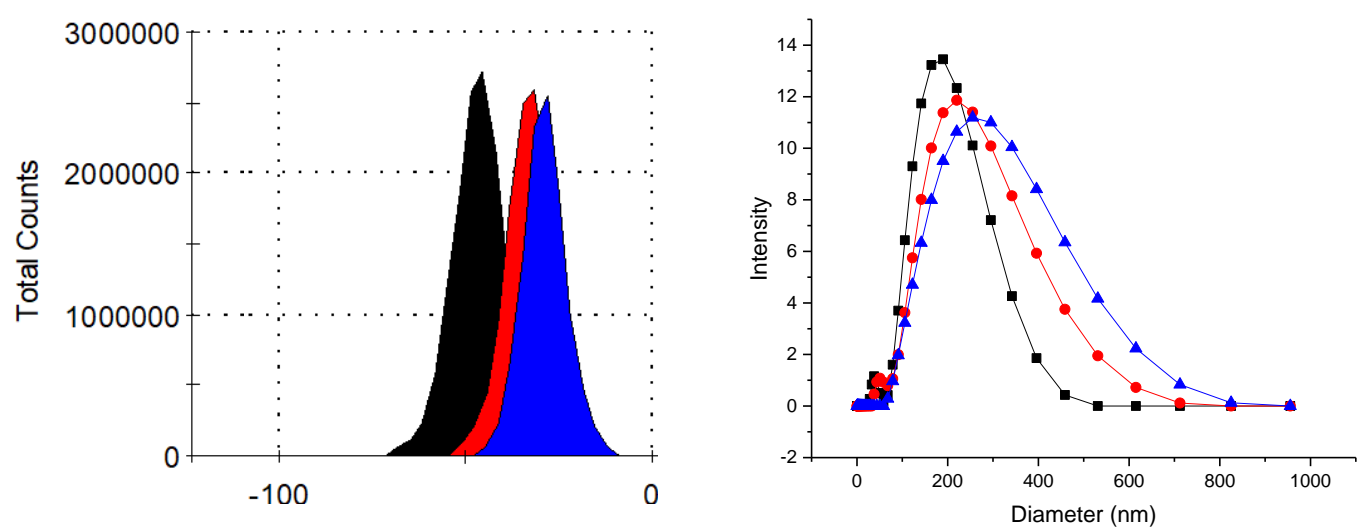

Figure 4: Zeta Potential (left) and size (right) measurements of each batch measured in $\mathrm{mV}$ and $\mathrm{nm}$ respectively.

\section{Structural Conclusions}

Elemental analysis showed an increase in the number of $\left[\mathrm{Fe}(\mathrm{CN})_{6}\right]^{4-}$ site vacancies as the copper to iron ratio was increased. XRD while identifying each batch as cubic $\mathrm{Cu}-\mathrm{HCF}$, also showed that as the copper content was increased the $\left[\mathrm{Fe}(\mathrm{CN})_{6}\right]^{4-}$ site vacancies within the structure began to organise leading to the creation of multiple copper environments. As JiménezGallegos et al. pointed out, in a random distribution of vacancies the structure is assigned the Fm3m structural model and all copper sites are equivalent, with each copper possessing four $\mathrm{CN}$ ligands plus two water molecules, $\mathrm{Cu}(\mathrm{NC})_{4}\left(\mathrm{H}_{2} \mathrm{O}\right)_{2}$. However, in an ordered vacancy distribution, the $1 \mathrm{~b}$ and $3 \mathrm{~d}$ sites have different occupation factors and this leads to different coordination environments for the copper atom. FT-IR confirmed this showing the $\mathrm{v}(\mathrm{Cu}-\mathrm{N})$ stretch as a broad singlet at low copper concentration (batch 2) which then split into a discernible doublet as the copper to iron ratio was increased, (Figure 3 - Inset II). FT-IR also showed the simultaneous appearance of new well defined co-ordinated water peaks again indicating new copper environments being formed. Recalculating the copper to iron ratio where $\mathrm{Cu}$ equals 1 , we find that the three batches have a $\mathrm{Cu}$ to $\mathrm{Fe}$ ratio of 1:0.8, 1:0.6 and 1:0.5. Therefore, we can view the three batches of $\mathrm{Cu}-\mathrm{HCF}$ produced here as having either $20 \%, 40 \%$ or $50 \%$ of their $\mathrm{Fe}(\mathrm{CN})_{6}$ units "missing". If the $\mathrm{Cu}-\mathrm{HCF}$ structure is pictured as a 3-dimensional 
cage of ever repeating $\mathrm{Cu}-\mathrm{N}-\mathrm{C}-\mathrm{Fe}$ units (Figure 1) where each Fe atom supplies $6 \mathrm{CN}$ ligands, it stands that when a Fe is missing the corresponding $6 \mathrm{CN}$ ligands will also be missing. The coordination sphere of any adjacent copper is then completed with water ligands. The more iron sites which are vacant the higher the dependency on water to complete the structure, (Figure 5). Finally, DLS showed that the Fe vacancies are not just internal but are present on the particles surface as well. As the $\mathrm{Cu}: \mathrm{Fe}$ ratio is increased the particles surfaces becoming more neutral as the ratio of $\mathrm{Fe}-\mathrm{CN}^{-}$to $\mathrm{Cu}-\mathrm{OH}_{2}$ surface groups decreases.

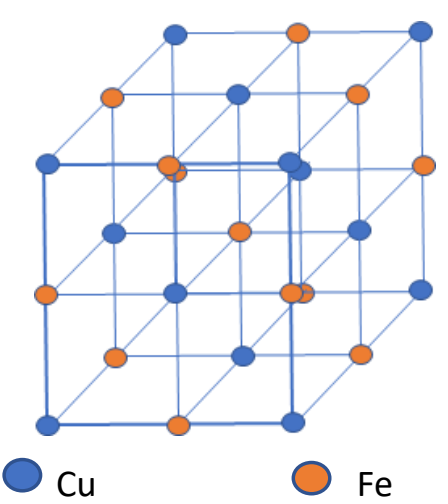

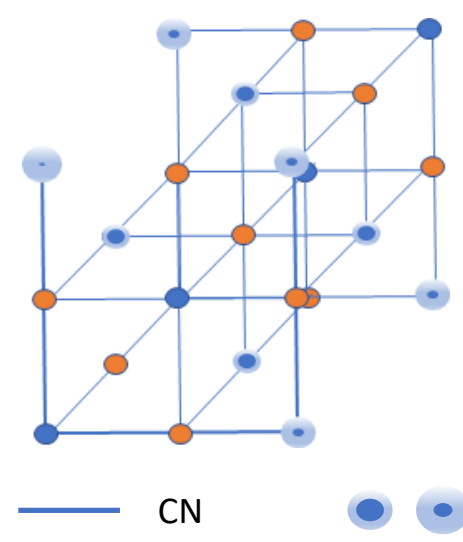

CN

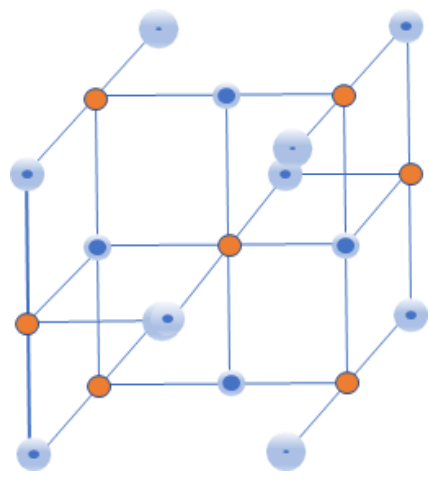

Hydrated Cu with 3, 2 or 1

Figure 5: From left to right $\mathrm{Cu}-\mathrm{HCF}$ with 0,20 , and $50 \%$ of the $\mathrm{Fe}(\mathrm{CN})_{6}{ }^{4-}$ sites vacant. As the number of vacancies increase the materials dependence on water to complete the structure increases.

\section{Link between thermal stability and $\mathrm{Cu}-\mathrm{HCF}$ type}

Each batch was examined in air between $30-300{ }^{\circ} \mathrm{C}$, Figure 6. This temperature range was chosen to allow us to more closely monitor water loss, and with it the eventual decomposition of the $\mathrm{CN}$ ligand. All three samples show mass loss from $60-120-125{ }^{\circ} \mathrm{C}$ and a distinctive shoulder between $150-200{ }^{\circ} \mathrm{C}$ There is however, a notable difference is the position of the shoulder between batch 2 and batches 3/4. While it is at around $170 \pm 4{ }^{0} \mathrm{C}$ for batches 3 and 4 it is $197{ }^{\circ} \mathrm{C}$ for batch 2. [Note: The total degree of mass loss across the temperature range is quite different for all three batches; however, this can be explained by the difference in particle stoichiometry across the series.] Finally, while batches 3 and 4 show a mass gain step at around $250{ }^{\circ} \mathrm{C}$ (indicating oxidation), batch 2 does not. Looking at the DSC, (Figure 6 - Inset), we see a number of distinct exothermic peaks corresponding to mass loss (or gains) between $90{ }^{\circ} \mathrm{C}$ 
and $260{ }^{\circ} \mathrm{C}$ in batches 3 and 4, while batch 2 shows only a rising diagonal line with little fine structure.

To more fully understand these results and to attribute each mass loss and shoulder to water loss and/or cyano decomposition, the samples were heating to certain temperatures within the above range and examined using FT-IR.

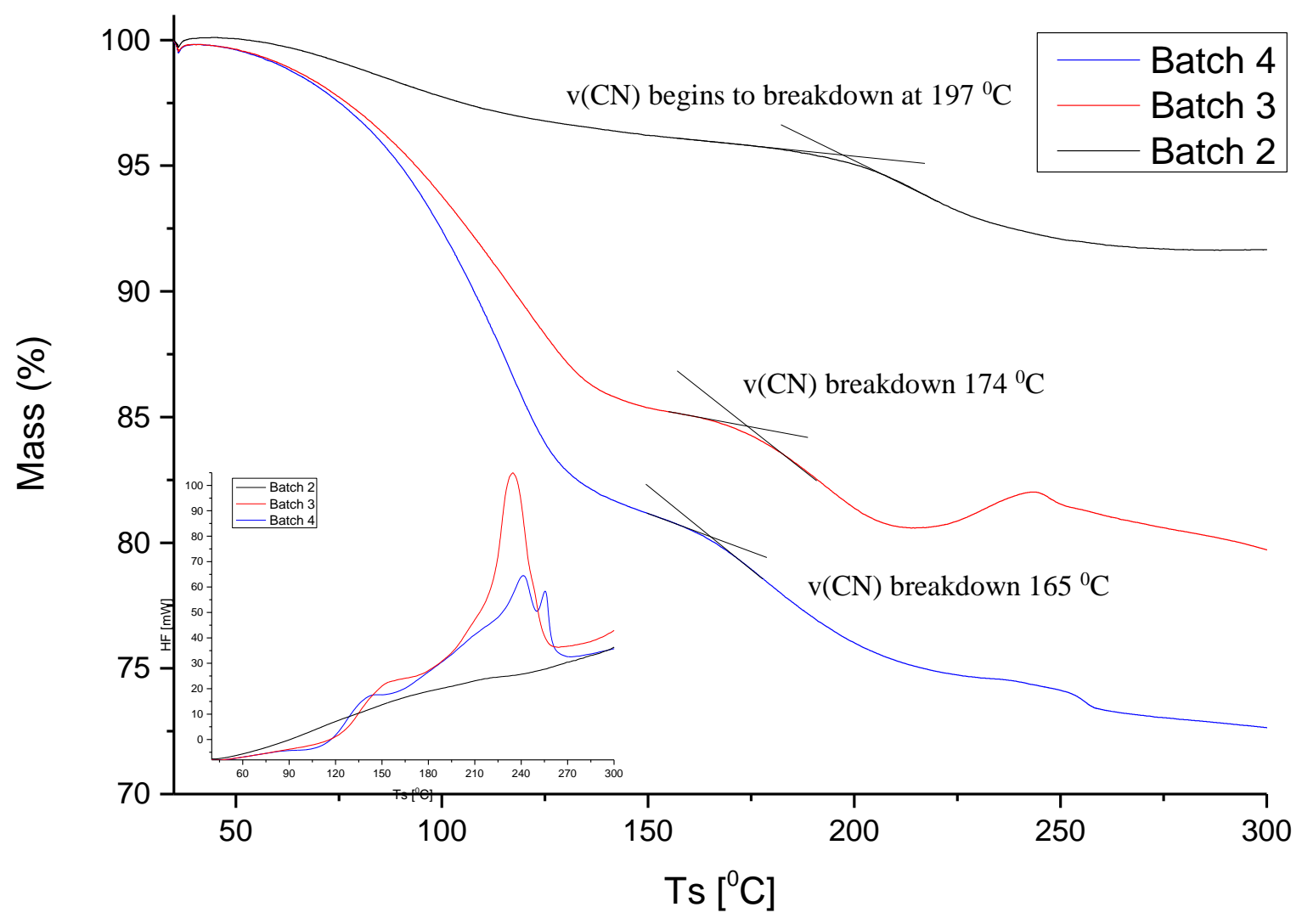

Figure 6: TGA and DSC (inset) of batches 2 (blue), 3 (green) and 4 (red) $\mathrm{Cu}-\mathrm{HCF}$.

Each batch was firstly heated to $140{ }^{\circ} \mathrm{C}$ for 4 hours $\left(2{ }^{\circ} \mathrm{C} / \mathrm{min}\right)$ in air. This process was continued jumping $10{ }^{\circ} \mathrm{C}$ per treatment until the $\mathrm{v}(\mathrm{CN})$ stretch was undetectable. The relative strength and position of the $\mathrm{v}(\mathrm{CN})$ was used to determine thermal cyano decomposition and link the thermal treatment with the structure of the material. Figure 7 shows batch 2 at room temperature, as well as after various heat treatments from $170{ }^{\circ} \mathrm{C}$ to $250{ }^{\circ} \mathrm{C}$. At $190{ }^{\circ} \mathrm{C}$ the $\mathrm{v}(\mathrm{CN})$ stretch has increased in strength and decreased in frequency by $6 \mathrm{~cm}^{-1}$. It has also narrowed slightly. This indicates an annealing effect has taken place as the heat removes defects from the structure. 


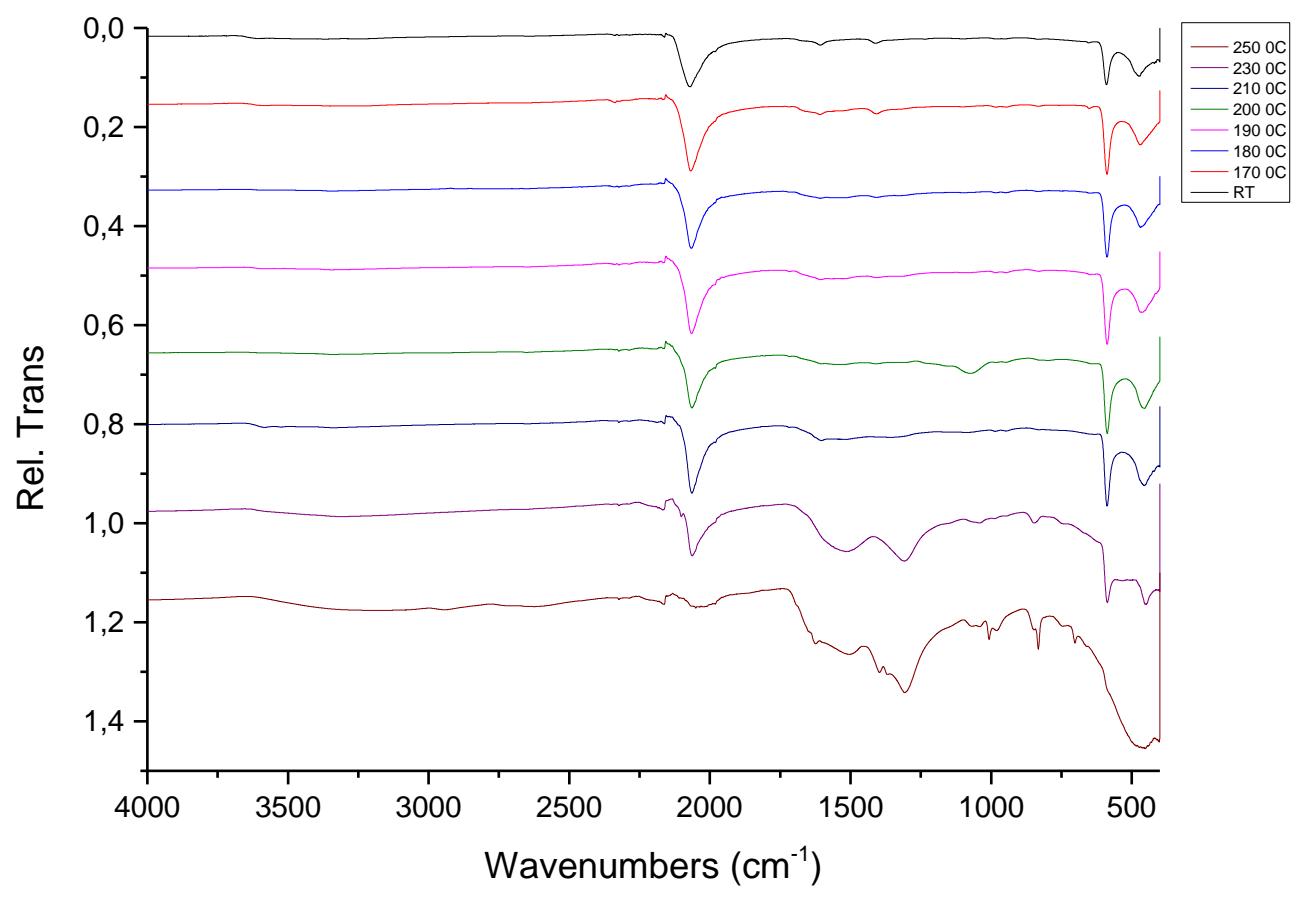

Figure 7: FT-IR of batch 2 at room temperature, as well as after various heat treatments from $1700 \mathrm{C}$ to 250 0C. Each scan corresponds to 4 hours at that temperature. The sample is the same one throughout the experiment.

This continues up to $210{ }^{\circ} \mathrm{C}$. However, at $230{ }^{\circ} \mathrm{C}$ the peak begins to decrease in strength, although it is still well structured. At $250{ }^{\circ} \mathrm{C}$ the peak has broken down. The beginnings of $\operatorname{KOCN}\left(2,160 \mathrm{~cm}^{-1}\right.$ and $\left.1,300 \mathrm{~cm}^{-1}\right)$ and carbonate humps $\left(1,400-1,700 \mathrm{~cm}^{-1}\right)$ are clearly present at $190{ }^{\circ} \mathrm{C}$ but become more and more noticeable as the temperature is increased, eventually dominating the spectra by $250{ }^{0} \mathrm{C} .{ }^{38}$

In batch 3 (Figure 8) we initially see the same annealing effect when the batch is heated in air. However, it does not last and as suggested previously by the TGA measurement the material begins to break down at much lower temperatures than batch 2 . When the sample is heated above $170{ }^{\circ} \mathrm{C}$ an almost $80 \%$ break down in the intensity of the $\mathrm{v}(\mathrm{CN})$ stretch is observed. No signal is observable in the M-L region. The KOCN peaks disappear at $190^{\circ} \mathrm{C}$ and a weak $\mathrm{Cu}-$ $\mathrm{HCF}$ (III) v(CN) stretch appears. At $200^{\circ} \mathrm{C}$ the $\mathrm{CN}$ ligand peaks have completely broken down. 


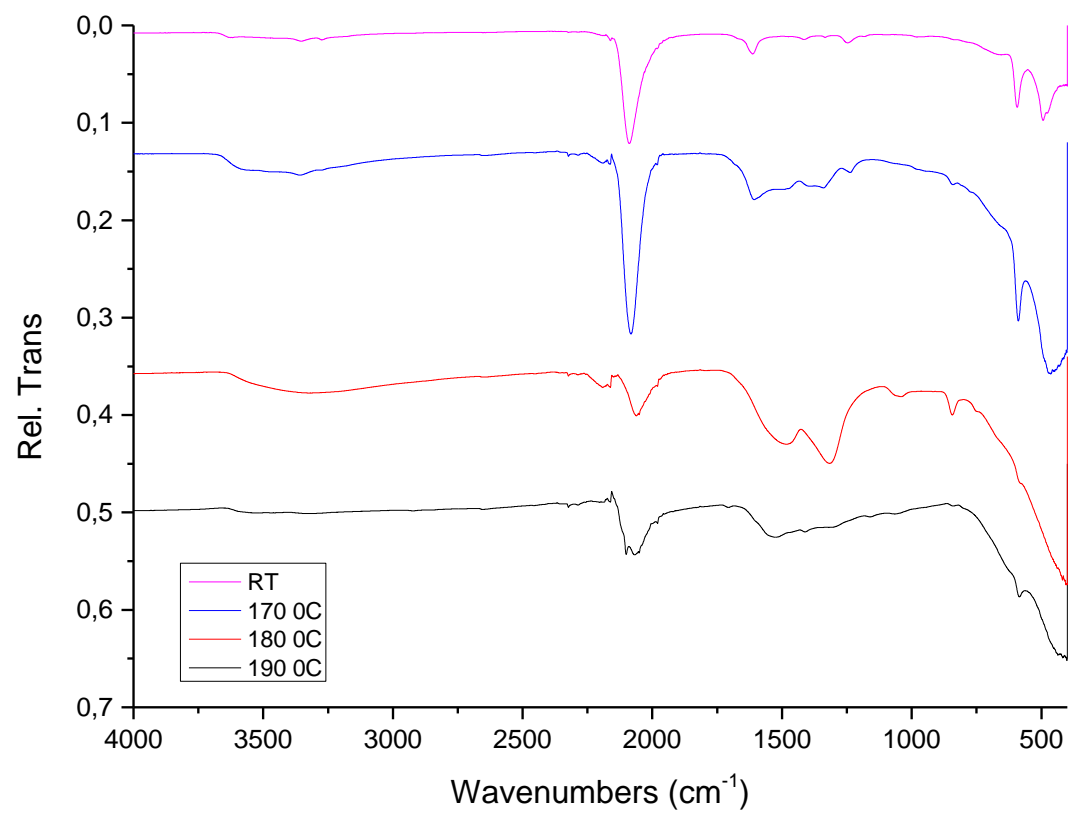

Figure 8: FT-IR of batch 3 at room temperature, as well as after various heat treatments from $170{ }^{\circ} \mathrm{C}$ to $250{ }^{0} \mathrm{C}$.

Finally, looking at batch 4 , when it was heated to $170{ }^{\circ} \mathrm{C} 75 \%$ of the intensity of the $\mathrm{v}(\mathrm{CN})$ stretch was lost, (Figure 9). It has decreased in frequency by almost $30 \mathrm{~cm}-1$ but has also broadened. Also a peak at $2,180 \mathrm{~cm}^{-1}$ is now present indicating the presence of $\mathrm{Cu}-\mathrm{HCF}$ (III). $\mathrm{KOCN}$ forms at $170{ }^{\circ} \mathrm{C}$. By $180{ }^{\circ} \mathrm{C}$ the $\mathrm{Cu}-\mathrm{HCF}(\mathrm{III}) \mathrm{v}(\mathrm{CN})$ peak has disappeared and the $\mathrm{Cu}$ HCF (II) stretch is almost gone.

Gathering these results together we see that depending on the particle stoichiometry $(\mathrm{Cu}: \mathrm{Fe}$ ratio) it is possible to synthesis $\mathrm{Cu}-\mathrm{HCF}$ where the cyano groups decompose at $180{ }^{\circ} \mathrm{C}, 190{ }^{\circ} \mathrm{C}$ or $250{ }^{\circ} \mathrm{C}$. The lower resistance to heat shown by batch 4 when compared to batches 3 and 2 , and of batch 3 when compared to batch 2 (Figure 7-9) is assumed to be due to the ever increasing structural water content moving from batch 2 to 4 . As water becomes more and more an integral part of the $\mathrm{Cu}-\mathrm{HCF}$ structure the material becomes more susceptible to thermal decomposition through water loss. The ever increasing structural dependence of $\mathrm{Cu}-\mathrm{HCF}$ on water is highlighted in the graphic in Figure 5. 


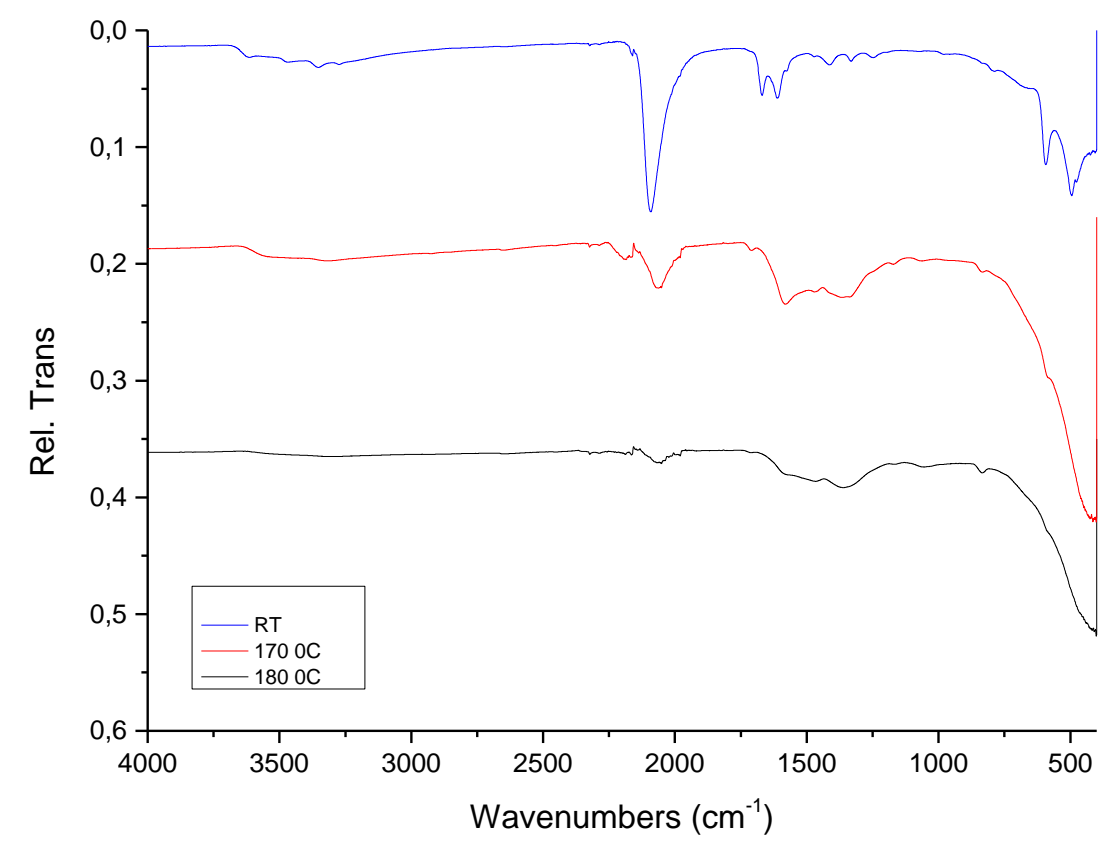

Figure 9: FT-IR of batch 4 at room T (blue) and after heating at $170{ }^{\circ} \mathrm{C}$ (red) and $180^{\circ} \mathrm{C}$ (black). the v(CN) stretch has decreased in strength by $75 \%$.

\section{Impact of the nature of the guest ion (K or Cs) on thermal stability}

Finally, the previously described FT-IT thermal studies were carried out on each batch after the $\mathrm{K}^{+}$guest ion was exchanged for $\mathrm{Cs}^{+}$. The $\mathrm{Cs}^{+}$sorption behaviour of these samples followed closely what has previously been reported by Takahashi et al; ${ }^{7}$ kinetic and isotherm data is available in the SI. The study showed an increase in the thermal stability of the cyano ligand throughout the series after $\mathrm{Cs}^{+}$was introduced into the structure. Batches 2 , 3 and 4 saw a $20^{\circ} \mathrm{C}, 50{ }^{\circ} \mathrm{C}$ and $40{ }^{\circ} \mathrm{C}$ increase respectively. Focusing on batch 3 , (Figure 10) EA of the exchanged sample showed no change in the $\mathrm{Cu}$ to Fe ratio loss during $\mathrm{Cs} / \mathrm{K}$ exchange. This indicates that there is no difference in the number of Fe vacancies after guest ion exchange and there is also no change in the amount of structural water present. 


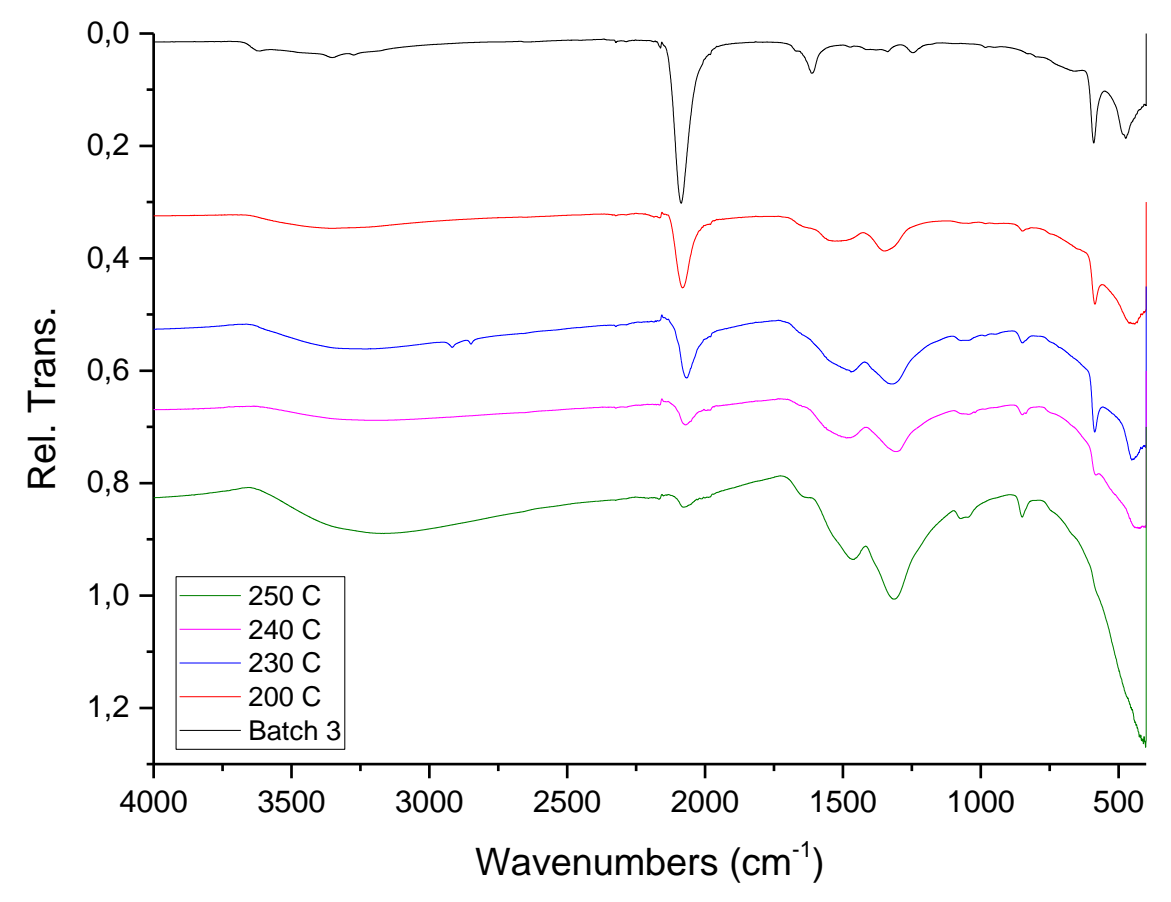

Figure 10: FT-IR of Cs exchanged batch 3 taken before thermal treatment began (black) and after thermal treatment at $200,230,240$ and $250^{\circ} \mathrm{C}$.

However, we believe that the presence of $\mathrm{Cs}^{+}$is indirectly responsible for the change in thermal stability as reported in Figure 10. v(CN) and M-L stretches are now stable and structured to $230{ }^{\circ} \mathrm{C}$. A weak v(CN) is still visible up to $250{ }^{\circ} \mathrm{C}$. This is an increase of $50^{\circ} \mathrm{C}$ when compared with the batch 3 before $\mathrm{Cs} / \mathrm{K}$ exchange. An explanation can be found in the metal-ligand region of the FT-IR spectra. As previously shown in Figure 3 there are two distinct $\mathrm{Cu}$ regions present in each batch. The literature has attributed this to the presence of a JahnTeller distortion within these materials. ${ }^{37}$ When $C s$ is added to each batch we see a change in this region with an inversion of the relative intensities of the $\mathrm{v}(\mathrm{Cu}-\mathrm{N})$ stretches, (Figure 11 and SI). The re-organisation of these stretches demonstrates a change in the degree of the copper centres Jahn-Teller distortion. That is the copper ligand bonds are lengthening (or shortening) after $\mathrm{Cs}$ is introduced. We believe that the $\mathrm{Cu}-\mathrm{O}$ bonds are shortening and strengthening after Cs is introduced into matrix. As reported $\mathrm{M}^{+}$guest ions are thought to interact with copper hexacyanoferrate structural water. ${ }^{25}$ Separately, as noted by Mähler et al. hydrated potassium $\mathrm{K}\left(\mathrm{OH}_{2}\right)_{7}$ has a $\mathrm{K}-\mathrm{O}$ distance of $2.81 \AA$ while hydrated caesium, $\mathrm{Cs}\left(\mathrm{OH}_{2}\right)_{8}$, shows a much weaker interaction with water possessing a Cs-O bond length of $3.081 \AA$. 


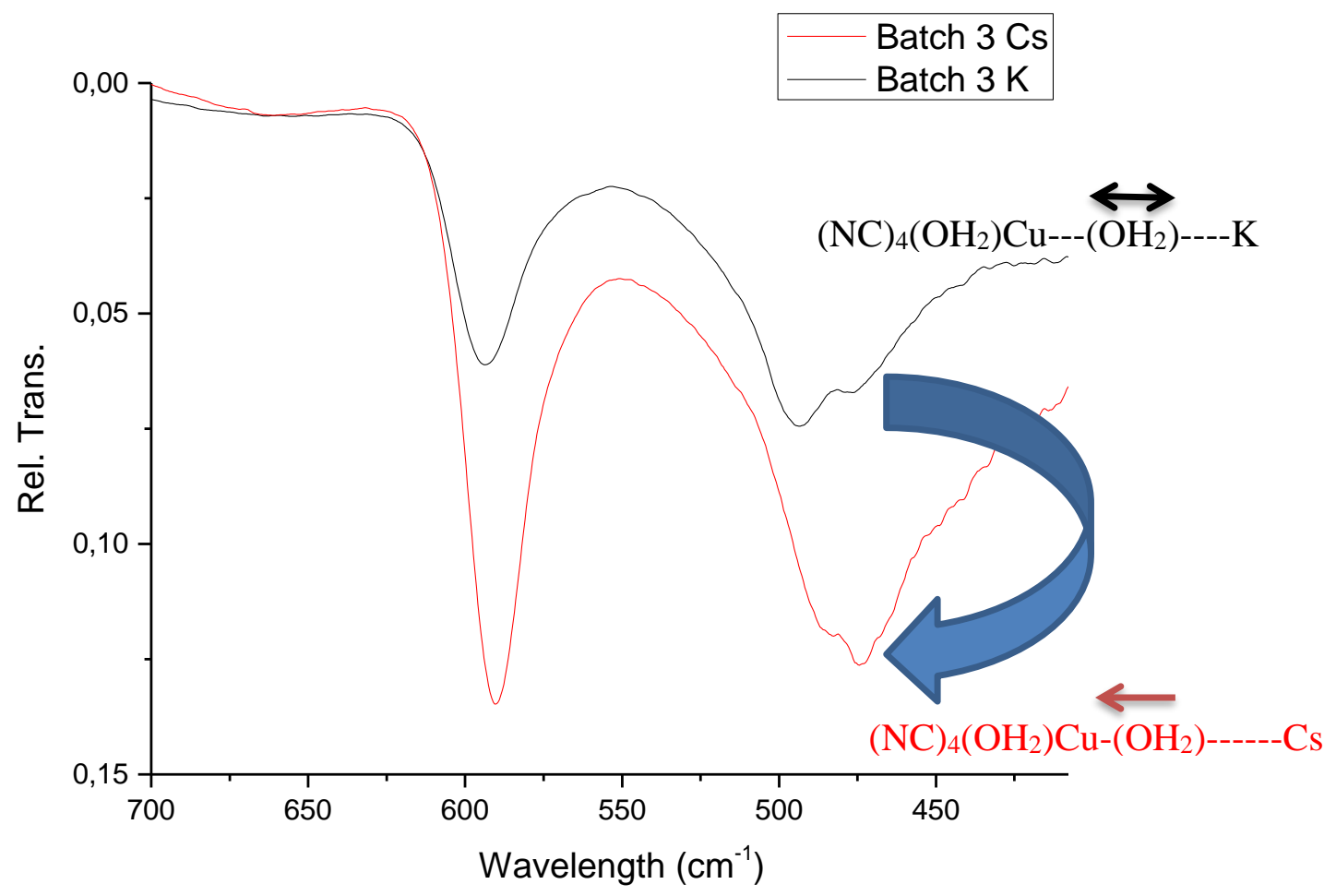

Figure 11: FT-IR of batch 3 before (black) and after (red) Cs/K exchange. Note the inversion of the relative strength of the $\mathrm{v}(\mathrm{Cu}-\mathrm{N})$ stretches.

By exchanging the $\mathrm{K}^{+}$guest ion for an ion with a significantly lower hydration energy and a weaker hydration shell (in this case $\mathrm{Cs}^{+}$) the copper is able to increase its hold on the partially shared structural water molecule. This in turn causes the $\mathrm{Cu}-\mathrm{O}$ bonds to shorten and strengthen. $25-26,27$, That is, the weaker the structural waters interaction with the guest ion, the stronger it will be with the copper. This strengthening of the bond between the copper and the structural water is what leads to an increase in thermal stability. Another possible explanation could be due to the stronger interaction of the larger $\mathrm{Cs}^{+}$ions with the cyano ligands, relative to that of the smaller $\mathrm{K}^{+}$ions. ${ }^{36}$ Enhanced guest ion interaction with the cyano ligands has been seen to coincide with a lengthening of the $\mathrm{Cu}-\mathrm{N}$, and subsequent shortening of the $\mathrm{Cu}-\mathrm{O}$ bonds. ${ }^{25}$ Again this leads to the same conclusion, a stronger $\mathrm{Cu}-\mathrm{O}$ bond. 


\section{Conclusions}

Here we report the tuning of the thermal stability of $\mathrm{Cu}-\mathrm{HCF}$ nanoparticles by varying the $\mathrm{Cu}$ to Fe reactant ratio. Elemental analysis showed it was possible to tune the $\mathrm{Fe}$ to $\mathrm{Cu}$ ratio and therefore the structural water content of the particles. This allowed us to alter the thermal sensitivity of the material. The nature of the guest ion was also shown to affect the decomposition temperature. The presence of $\mathrm{Cs}$ was seen to cause a change in the $\mathrm{Cu}$ coordination sphere as seen in FT-IR. As no change in the $\mathrm{Fe}$ to $\mathrm{Cu}$ ratio was detected this improved stability is believed to be a change in the degree of the Jahn-Teller distortion present in $\mathrm{Cu}-\mathrm{HCF}$. The next step is to perform a full structural analysis of the material before and after Cs exchange. This is currently been undertaken.

\section{Author Information}

\section{Corresponding Author}

Agnès Grandjean, CEA, DEN, Univ. Montpellier, DE2D, SEAD, Laboratory of Supercritical and Decontamination Processes, F-30207 Bagnols-sur-Cèze, France.

E-mail: agnes.grandjean@cea.fr

\section{Author Contributions}

The manuscript was written through contributions of all authors. All authors have given approval to the final version of the manuscript.

\section{Funding Sources}

Research was conducted in part by the Center for Hierarchical Waste Form Materials (CHWM), an Energy Frontier Research Center (EFRC) supported by the U.S. Department of Energy, Office of Basic Energy Sciences, Division of Materials Sciences and Engineering under Award DE-SC0016574. We also thank the EDDEM-CEA project for funding this work. 


\section{Acknowledgements}

Elemental Analysis was carries out by the Laboratoire de metallographie et d'analyses chimiques, CEA, DEN, Univ. Montpellier, DMRC, SA2I DEN/MAR/SA2I/DIR, CEA Marcoule, France.

\section{References}

1. Tao, Q. Q.; Zhang, X.; Prabaharan, K.; Dai, Y., Separation of cesium from wastewater with copper hexacyanoferrate film in an electrochemical system driven by microbial fuel cells. Bioresour. Technol. 2019, 278, 456-459.

2. Roh, H.; Kim, Y.; Kim, Y. K.; Harbottle, D.; Lee, J. W., Amino-functionalized magnetic chitosan beads to enhance immobilization of potassium copper hexacyanoferrate for selective $\mathrm{Cs}+$ removal and facile recovery. RSC Adv. 2019, 9 (2), 1106-1114.

3. Wang, J. L.; Zhuang, S. T.; Liu, Y., Metal hexacyanoferrates-based adsorbents for cesium removal. Coord. Chem. Rev. 2018, 374, 430-438.

4. Causse, J.; Tokarev, A.; Ravaux, J.; Moloney, M.; Barre, Y.; Grandjean, A., Facile one-pot synthesis of copper hexacyanoferrate nanoparticle functionalised silica monoliths for the selective entrapment of Cs-137. J. Mater. Chem. A 2014, 2 (25), 9461-9464.

5. Grandjean, A.; Delchet, C.; Causse, J.; Barré, Y.; Guari, Y.; Larionova, J., Effect of the chemical nature of different transition metal ferrocyanides to entrap Cs. Journal of Radioanalytical and Nuclear Chemistry 2016, 307 (1), 427-436.

6. Chang, S. Q.; Chang, L.; Han, W.; Li, Z.; Dai, Y. D.; Zhang, H. Q., In situ green production of Prussian blue/natural porous framework nanocomposites for radioactive Cs+ removal. Journal of Radioanalytical and Nuclear Chemistry 2018, 316 (1), 209-219.

7. Takahashi, A.; Tanaka, H.; Minami, K.; Noda, K.; Ishizaki, M.; Kurihara, M.; Ogawa, H.; Kawamoto, T., Unveiling Cs-adsorption mechanism of Prussian blue analogs: Cst-percolation via vacancies to complete dehydrated state. RSC Adv. 2018, 8 (61), 34808-34816.

8. Cabaud, C.; Barré, Y.; De Windt, L.; Gill, S.; Dooryhée, E.; Moloney, M. P.; Massoni, N.; Grandjean, A., Removing Cs within a continuous flow set-up by an ionic exchanger material transformable into a final waste form. Adsorption 2019.

9. Moloney, M. P.; Cabaud, C.; Massoni, N.; Stafford, S.; Gun'ko, Y. K.; Venkatesan, M.; Grandjean, A., Searching for the nano effect in CU-HCF (II) particles to improve Cs sorption efficiency: Highlighting the use of intrinsic magnetism. Colloids and Surfaces A: Physicochemical and Engineering Aspects 2019, $582,123758$.

10. Cabaud, C.; Barré, Y.; De Windt, L.; Gill, S.; Dooryhée, E.; Moloney, M. P.; Massoni, N.; Grandjean, A., Removing Cs within a continuous flow set-up by an ionic exchanger material transformable into a final waste form. Adsorption 2019, 25 (4), 765-771.

11. Zong, Y.; Zhang, Y.; Lin, X.; Ye, D.; Qiao, D.; Zeng, S., Facile synthesis of potassium copper ferrocyanide composite particles for selective cesium removal from wastewater in the batch and continuous processes. RSC Adv. 2017, 7 (50), 31352-31364.

12. Hwang, K. S.; Park, C. W.; Lee, K. W.; Park, S. J.; Yang, H. M., Highly efficient removal of radioactive cesium by sodium-copper hexacyanoferrate-modified magnetic nanoparticles. Colloid Surf. A-Physicochem. Eng. Asp. 2017, 516, 375-382.

13. Kim, Y. K.; Kim, T.; Kim, Y.; Harbottle, D.; Lee, J. W., Highly effective Cs+ removal by turbidityfree potassium copper hexacyanoferrate-immobilized magnetic hydrogels. J. Hazard. Mater. 2017, 340, 130-139. 
14. Kim, Y. K.; Bae, K.; Kim, Y.; Harbottle, D.; Lee, J. W., Immobilization of potassium copper hexacyanoferrate in doubly crosslinked magnetic polymer bead for highly effective $\mathrm{Cs}+$ removal and facile recovery. J. Ind. Eng. Chem. 2018, 68, 48-56.

15. Motl, A.; John, J.; Sebesta, F., Composite absorbers of inorganic ion-exchangers and polyacrylonitrile binding matrix - V. Influence of ionising radiation on the leachability of Cs-137 from cemented composite NiFC-PAN absorber. Journal of Radioanalytical and Nuclear Chemistry 1997, 222 (1-2), 205-207.

16. Michel, C.; Barré, Y.; De Windt, L.; de Dieuleveult, C.; Brackx, E.; Grandjean, A., lon exchange and structural properties of a new cyanoferrate mesoporous silica material for Cs removal from natural saline waters. Journal of Environmental Chemical Engineering 2017, 5 (1), 810-817.

17. Catala, L.; Mallah, T., Nanoparticles of Prussian blue analogs and related coordination polymers: From information storage to biomedical applications. Coord. Chem. Rev. 2017, 346, 32-61.

18. Mayer, M.; Dedovets, D.; Guari, Y.; Larionova, J.; Long, J.; Causse, J., Synthesis of poly(diallyldimethylammonium) capped copper hexacyanoferrate (CuHCF) nanoparticles: An efficient stabiliser for Pickering emulsions. J. Colloid Interface Sci. 2017, 505, 364-372.

19. Boles, M. A.; Ling, D.; Hyeon, T.; Talapin, D. V., The surface science of nanocrystals. Nat. Mater. 2016, 15 (2), 141-153.

20. Yoffe, A. D., Semiconductor quantum dots and related systems: electronic, optical, luminescence and related properties of low dimensional systems. Adv. Phys. 2001, 50 (1), 1-208.

21. Rajesh, K. M.; Ajitha, B.; Ashok Kumar Reddy, Y.; Suneetha, Y.; Sreedhara Reddy, P., Synthesis of copper nanoparticles and role of pH on particle size control. Materials Today: Proceedings 2016, 3 (6), 1985-1991.

22. Guardia, P.; Labarta, A.; Batlle, X., Tuning the Size, the Shape, and the Magnetic Properties of Iron Oxide Nanoparticles. The Journal of Physical Chemistry C 2011, 115 (2), 390-396.

23. Hu, M.; Chen, J. Y.; Li, Z. Y.; Au, L.; Hartland, G. V.; Li, X. D.; Marquez, M.; Xia, Y. N., Gold nanostructures: engineering their plasmonic properties for biomedical applications. Chem. Soc. Rev. 2006, 35 (11), 1084-1094.

24. Moloney, M. P.; Gun'ko, Y. K.; Kelly, J. M., Chiral highly luminescent CdS quantum dots. Chem. Commun. 2007, (38), 3900-3902.

25. Wardecki, D.; Ojwang, D. O.; Grins, J.; Svensson, G., Neutron Diffraction and EXAFS Studies of $\mathrm{K} 2 \mathrm{x} / 3 \mathrm{Cu}[\mathrm{Fe}(\mathrm{CN}) 6] 2 / 3 \cdot \mathrm{nH} 2 \mathrm{O}$. Crystal Growth \& Design 2017, 17 (3), 1285-1292.

26. Tachikawa, H.; Haga, K.; Yamada, K., Mechanism of K+, Cs+ ion exchange in nickel ferrocyanide: A density functional theory study. Computational and Theoretical Chemistry 2017, 1115, 175-178.

27. Mähler, J.; Persson, I., A Study of the Hydration of the Alkali Metal Ions in Aqueous Solution. Inorganic Chemistry 2012, 51 (1), 425-438.

28. Gotoh, A.; Uchida, H.; Ishizaki, M.; Satoh, T.; Kaga, S.; Okamoto, S.; Ohta, M.; Sakamoto, M.; Kawamoto, T.; Tanaka, H.; Tokumoto, M.; Hara, S.; Shiozaki, H.; Yamada, M.; Miyake, M.; Kurihara, M., Simple synthesis of three primary colour nanoparticle inks of Prussian blue and its analogues. Nanotechnology 2007, 18 (34), 6.

29. Akerblom, I. E.; Ojwang, D. O.; Grins, J.; Svensson, G., A thermogravimetric study of thermal dehydration of copper hexacyanoferrate by means of model-free kinetic analysis. Journal of Thermal Analysis and Calorimetry 2017, 129 (2), 721-731.

30. Soek, R. N.; Schmidt, A.; Winnischofer, H.; Vidotti, M., Anisotropic behavior of layer-by-layer films using highly disordered copper hexacyanoferrate(II) nanoparticles. Appl. Surf. Sci. 2016, 378, 253258.

31. Ojwang, D. O.; Grins, J.; Wardecki, D.; Valvo, M.; Renman, V.; Häggström, L.; Ericsson, T.; Gustafsson, T.; Mahmoud, A.; Hermann, R. P.; Svensson, G., Structure Characterization and Properties of K-Containing Copper Hexacyanoferrate. Inorganic Chemistry 2016, 55 (12), 5924-5934.

32. Avila, M.; Reguera, L.; Rodríguez-Hernández, J.; Balmaseda, J.; Reguera, E., Porous framework of $\mathrm{T} 2[\mathrm{Fe}(\mathrm{CN}) 6] \cdot \mathrm{xH} 2 \mathrm{O}$ with $\mathrm{T}=\mathrm{Co}, \mathrm{Ni}, \mathrm{Cu}, \mathrm{Zn}$, and $\mathrm{H} 2$ storage. Journal of Solid State Chemistry 2008, 181 (11), 2899-2907. 
33. Jiménez-Gallegos, J.; Rodríguez-Hernández, J.; Yee-Madeira, H.; Reguera, E., Structure of Porous Copper Prussian Blue Analogues: Nature of Their High H2 Storage Capacity. The Journal of Physical Chemistry C 2010, 114 (11), 5043-5048.

34. Gil, D. M.; Avila, M.; Reguera, E.; Pagola, S.; Inés Gómez, M.; Carbonio, R. E., Lead hexacyanoferrate(II) tetrahydrate: Crystal structure, FTIR spectroscopy and thermal decomposition studies. Polyhedron 2012, 33 (1), 450-455.

35. Ghosh, S. N., Infrared spectra of the Prussian blue analogs. Journal of Inorganic and Nuclear Chemistry 1974, 36 (11), 2465-2466.

36. Lejeune, J.; Brubach, J.-B.; Roy, P.; Bleuzen, A., Application of the infrared spectroscopy to the structural study of Prussian blue analogues. Comptes Rendus Chimie 2014, 17 (6), 534-540.

37. Gellings, P. J., Structure of some Hexacyanoferrates (II) of the Type K2MIIFe(CN)6. In Zeitschrift für Physikalische Chemie, 1967; Vol. 54, p 296.

38. De Marco, D.; Marchese, A.; Migliardo, P.; Bellomo, A., Thermal analysis of some cyano compounds. Journal of thermal analysis 1987, 32 (3), 927-937. 